\title{
Conhecimento e uso da medicina alternativa entre alunos e professores de primeiro grau*
}

\author{
Knowledge and use of alternative medicine by elementary school children and \\ teachers
}

Marilena Gomes dos Santos, Ângela Guimarães Pinto Dias, Marcelo Moreira Martins

Centro de Pesquisas "René Rachou"FIOCRUZ - Belo Horizonte - Brasil (M.G.S., A.G.P.D., M.M.M.)

\begin{abstract}
Como parte de um Projeto de Educaçāo em Saúde, investigou-se o conhecimento e como são utilizadas as práticas populares de cura, de modo a desenvolver e ampliar na escola, as possibilidades já existentes de discussão crítica $\theta$ construtiva dentro do programa de saúde. Espera-se com isso poder resgatar saberes e valorizar esse conhecimento não sistemattzado, presente na prátlca des populaçōes ainda de forma marginalizada e controvertida. Foram aplicados questionários entre 110 professores a 162 alunos das $1^{\text {B a }} 4^{\text {g }}$ séries do $1^{\circ}$ grau de quatro escolas (P.L.S.L., P.H.A., P.A.M.M. e A.M.G.) da periferia de Belo Horizonte. Sendo que, as quest $\chi e s$ apresentadas foram respondidas somente por 105 docentes. Vinte $\theta$ três $(32,4 \%)$ (entre $71(67,6 \%)$ ) acreditam em dons especiais de cura; dos 105 (95,4\%) que responderam sobre se acham que certas doenças podem ser tratadas com remédios caseiros, somente $69(65,7 \%)$ acreditam que sim; $54(78,3 \%)$ dentre esses, associaram a cura da doença com a planta medicinal e 15 (21,7\%) indicam o remédio sem associaçāo com a doença; 36 (34,3\%) professores citaram a doença sem relacioner as ervas medicinais. já, $101(62,3 \%)$ alunos acreditam qư os remédios caseiros são positivos para algumas doenças. Entre os alunos e professores foram mencionadas doenças diversas, sintomas a órgāos que podem ser curados por plantas medicinais, rezas ou benzedeiras. Um pouco mais de $50 \%$ dos dojs grupos de alunos $\left(1^{4}, 2^{4}, 3^{\mathbf{l}} \theta^{4^{4}}\right.$ séries) viverm entre famílias que procuram benzedeiras como alternativa de cura. Foram Indicadas pelos professores e alunos mais de 50 plantas ou composiçōes de partes de plantas. Conclul-se, que a medicina alternativa é conhecida $\theta$ utilizada peia amostra estudada.
\end{abstract}

Conhecimentos, atitudes e pratica. Medicina altemativa. Educaçâo em saúde. Saúde escolar.

\section{Introdução}

A história mostra-nos que há séculos o homem tem procurado alternativas para eliminar seus males físicos, de forma empírica ou intuitiva ${ }^{\mathrm{6}, 712}$.

Segundo Lozoyå, a partir da década de 70 começou-se a questionar uma nova definição do que seria saúde, consequientemente, aumentou também a conscientização da importância da natureza no equilíbrio do homem, já utilizada há séculos pelos orientais, estimulando a busca de aiternativas mantenedoras de saúde e prevenção das doenças ${ }^{10}$.

No Brasil muito se recebeu de influência dos africanos e principalmente do indígena da terra.
Muitas plantas "além de serem usadas como medicinais, fazem parte dos ritos afro-brasileiros para grande parte da populaçāo, têm poderes mágicos" (Oliveira ${ }^{10}, 1985$ ).

Em um país como o Brasil, com imensa extensāo geográfica, em espaços de grandes diversidades e peculariedades e, em diferentes circunstâncias e com diversas concepçoes, opiniōes e valores sobre a medicina popular, usa-se conjunto de técnicas, conhecimentos e práticas, que sāo incorporadas e respeitadas no cotidiano, cristalizadas nos hábitos, nas tradiçóes e nos costumes. Sem que se preste atençăo, elas săo praticadas diariamente no meio em que vivemos ${ }^{10}$. Curandeiros, médiuns, 
raizeiros, parteiras e a população em geral utilizam ervas medicinais em um verdadeiro sincretismo de concepções. Dessa forma, Camargo ${ }^{2}$ admite a existência, no Brasil, de uma medicina popular de conotações mágico-religiosas, presa a um universo sacralizado controlador das forças sobrenaturais, de certa forma responsáveis pelo aparecimento e cura das doenças do corpo e do espírito. Para Commune $^{3}$ também as rezas entre os ritos religiosos e mágicos se sobressaem na defesa dos problemas de saúde. No ponto de vista de Cury ${ }^{4}$, as forças religiosas voltam a interessar os estudiosos do Brasil já nāo como resíduos de uma mentalidade atrasada e bárbara, mas como estímulos poderosos à vida em comum, saídas grupais do desespero e da opressảo.

Embora existam vários estudos a respeito do uso, eficácia e toxicidade, de plantas medicinais, a literatura científica ainda é pobre no sentido de se conhecer o que pensam as populações a esse respeito, o nível de conhecimento que possuem, a crença e os tratamentos feitos com os remédios caseiros.

Em se tratando da escola fundamental e, tendo em vista o papel que ela representa na formação do indivíduo e a sua potencialidade de estimular a criaçăo de conceitos, assim como sua atitude questionadora e crítica em relaçâa à realidade, objetivou-se investigar o conhecimento das práticas populares de saúde e como são utilizadas e, a opiniaao de escolares e docentes de escolas de primeiro grau.

\section{Materlal e Método}

Informaçzes gerais, localização das escolas, critérios de escolha das escolas $e$, instrumento utilizado - Foi realizado durante quatro anos, programa de educação para a saúde em duas escolas municipais, experimentais (L.S.L. e P.A.M.M.) e duas outras (P.H.A e A.M.G.). Na primeira daquelas escolas experimentais houve intervençāo dos pesquisadores no programa educacional, para apresentar novas metodologias, enquanto, na segunda, não houve intervenção externa e os professores utilizaram apenas métodos tradicionais de ensino. $E$ isso, como parte de projeto maior, em relação à saúde, realizado pelo Laboratório de Esquistossomose do Centro de Perquisas " René Rachou" - FIOCRUZ, objetivando o controle dessa endemia.

A população estudada é procedente da Capital de Minas Gerais, de outras regiōes do Estado de Minas Gerais, além do Norte e Nordeste do País. Isso mostrou, com essa diversificação regional, o conhecimento e os comportamentos frequientes em tais áreas.

Duas das escolas eram localizadas no bairro Gorduras, Belo Horizonte (L.S.L. e P.H.A.), região onde se aloja grande número de pessoas que vivem em condições de extrema pobreza (socioeconômica e cultural). A terceira, localiza-se no Vale do Jatobá (P.A.M.M.), em cuja redondeza existem vilas e favelas de grande precariedade. Finalmente, a quarta, encontrava-se na localidade denominada Barreiro de Cima (A.M.G.), na vizinhança de pequenos conjuntos de apartamentos populares onde existe melhores condiçōes de saneamento básico. A populaçāo desta última é constituída de filhos de operários das indústrias circunvizinhas $\mathrm{e}$ de indivíduos que possuem subempregos.

Como critério de caracterizaçāo das escolas, foram selecionadas duas de prevalência maior de parasitoses e duas de menos prevalência, de acordo com os resultados de estudo prévio, por parte do Departamento de Parasitoses Municipal e do Laboratório de Esquitossomose do CPqRR, FIOCRUZ*. Posteriormente, foram feitos levantamentos pelo citado projeto, cujos resultados revelaram-se equivalentes a esse, ou seja, $68,0 \%$ e $46,0 \%$ escolares infectados pelas parasitoses nas escolas experimentais (L.S.L. e P.A.M.M.) e, $76,0 \%$ e $24,0 \%$ nas escolas controle (P.H.A. e A.M.G.). Os alunos foram escolhidos através da tabela de números aleatórios e o estudo abrangeu a totalidade dos docentes.

Instrumento utilizado - $\mathrm{O}$ instrumento utilizado para a obtenção de dados foi um questionário (anexo) aplicado em 110 professores, em 80 alunos de primeira e segunda séries, e 82 da terceira e quarta séries do primeiro grau. Os questionários, semi-estruturados, foram aplicados por quatro bolsistas, estudantes de biologia e psicologia, previamente treinados para dar explicações quanto à maneira de se proceder. Os alunos das primeira e segunda sếries responderam às questões oralmente, e as respostas eram transcritas pelos pesquisadores; os demais preencheram, eles próprios, os questionários. Foram criados critérios operacionais para análise das questōes abertas.

Aos indivíduos recolhidos foi solicitado previamente consentimento para sua participação da pesquisa. Foi feito inicialmente um "rapport" com as crianças tentando minimizar possíveis tensões. A aplicação do questionário foi feita na respectiva escola.

\footnotetext{
* Dados inéditos.
} 
$\mathrm{Na}$ análise estatística, utilizou-se o qui-quadrado a 0,05 de significância.

\section{Resultados}

Crença do professor em dons especiais de cura - Somente $71(64,5 \%)$ professores responderam sobre essa questão: para $23(32,4 \%)$, algumas doenças podem ser tratadas por certas pessoas com dons especiais de cura, $48(67,6 \%)$ não acreditam. Entre os $23(32,4 \%), 3(13,0 \%)$ acreditam que a "bronquite, a asma, o sapinho e os sentimentos podem ser curados com simpatia", $1(4,3 \%)$ crê "na bençāo para quebranto", $14(60,9 \%)$ acreditam que os "desmaios, doenças psicológicas e feridas são sintomas que poderāo ser tratados por pessoas com dons especiais de cura"; $5(7,0 \%)$ entre $71(64,5 \%)$ professores generalizaram a resposta e responderam que acreditam em "práticas populares".

Opinião dos professores em relação d̀ crença no tratamento com remédios caseiros, à associação da doença e/ou sintoma com as ervas medicinais - Cento e cinco $(95,4 \%)$ professores deram a sua opinião. Um grande número, 69 $(65,7 \%)$ acreditam que os remédios caseiros podem tratar qualquer doença, $36(34,3 \%)$ crêem que eles podem tratar certas doenças. Além de acreditarem nos remédios caseiros, $54(51,4 \%)$ indicam a doença e qual a planta medicinal que deve ser utilizada, $15(21,7 \%)$ citaram as ervas sem as associar às doenças (cipo amarelo, ervas generalizadas, folha de mangabeira, confrei). Foram citadas 36 doenças que podem ser tratadas com plantas medicinais, por exemplo: anemia, bronquite, caxumba, desidrataçảo, diarréia, dores abdominais, dor de ouvido, erupçōes na pele, gastroenterite, infecções generalizadas, infecção urinária, insolaçāo, mal cheiro corporal, mal estar, sangramento nasal, sarampo, úlceras e vermes. É representativo o número de citações feitas pelo corpo docente em relação não só ao acreditar, mas relacionar sintomas e doenças com as ervas medicinais (Tabela 1).

Opiniōes dos alunos sobre as doenças que podem ser tratadas com remédios caseiros - Entre os alunos das primeira e segunda séries $(\mathrm{n}=80), 14$ $(17,5 \%)$ não responderam, $66(82,5 \%)$ deram sua opiniầo, $46(69,7 \%)$ acreditam que certas doenças podem ser tratadas por remédios caseiros, alem de fazerem o uso dos mesmos, $20(30,3 \%)$ negam tal possibilidade. Entre os da terceira e quarta séries $(n=82), 15(18,3 \%)$ não responderam, $67(81,7 \%)$ deram a sua opinião, $55(82,1 \%)$ acreditam no benefício dos remédios caseiros, $10(14,9 \%)$ não acreditam, $2(3,0 \%)$ acreditam às vezes.

A opinião dos $128(79,0 \%)$ alunos, (primeira à quarta séries) em relaçāo às doenças que podem

Tabela 1 - Resposta sobre à asscciação da doença e/ou sintoma com os remédios caseiros, professores de quatro escoias municipais da periferia de Belo Horizonte, Minas Gerals.

\begin{tabular}{|c|c|c|c|}
\hline Classlficação & Doença e/ou sintoma & Plante indicada & $\begin{array}{l}\text { Número de citaçōes } \\
\text { asssociada à planta }\end{array}$ \\
\hline $\begin{array}{l}\text { Doenças das vias } \\
\text { respiratórias }\end{array}$ & $\begin{array}{l}\text { Coqueluche } \\
\text { Gripe, Resfrlado } \\
\text { Infecçōes } \\
\text { Sarampo } \\
\text { Doenças respiratórias } \\
\text { (generalizadas) }\end{array}$ & $\begin{array}{l}\text { Nabo com açúcar } \\
\text { Xarope de flores, Mel, } \\
\text { Limão, Agriăo, Poejo, } \\
\text { Folha de Laran]a } \\
\text { Trançagem } \\
\text { Sabougueiro } \\
\text { Vaporização com folha } \\
\text { de Eucalipto }\end{array}$ & $\begin{array}{l}3 \\
4 \\
4 \\
4\end{array}$ \\
\hline Parasitoses & $\begin{array}{l}\text { Lombriga } \\
\text { Piolho }\end{array}$ & $\begin{array}{l}\text { Santa Marla, Pitanga } \\
\text { Vinagre, Limão com sal }\end{array}$ & $\begin{array}{l}4 \\
4\end{array}$ \\
\hline Problemas em órgāos & $\begin{array}{l}\text { Rins } \\
\text { Est8mago } \\
\text { Figado }\end{array}$ & $\begin{array}{l}\text { Quebra-pedra } \\
\text { Bálsamo, Boldo, Hortelà } \\
\text { Picāo }\end{array}$ & $\begin{array}{r}2 \\
21 \\
14\end{array}$ \\
\hline Problemas emocionais & Tensāo nervosa & Camomila & 2 \\
\hline Sintomas gerais & $\begin{array}{l}\text { Dor de cabeça } \\
\text { Gazes } \\
\text { Dor de barriga } \\
\text { Diarréia }\end{array}$ & $\begin{array}{l}\text { Erva Cidreira, Marcela } \\
\text { Erva Doce } \\
\text { Erva Doce, Macaé com } \\
\text { Bicartonato, Marcela } \\
\text { Hortelā, Erva Cidreira, } \\
\text { Marcela }\end{array}$ & $\begin{array}{r}5 \\
5 \\
12 \\
44\end{array}$ \\
\hline
\end{tabular}


Tabela 2 - Sintomas elou doenças que podem ser tratadas com remédios caseiros na opiniaxo de alunos de primeira à quarta séries de escolas municipais da periferia de Belo Horizonte, Minas Gerais. N. 128.

\begin{tabular}{|c|c|c|c|c|c|}
\hline \multirow{2}{*}{ Sintomas / Doenças } & \multicolumn{2}{|c|}{ 1" a 2" séries } & \multirow{2}{*}{ Sintomas / Doenças } & \multicolumn{2}{|c|}{$3^{a}$ a $4^{a}$ séries } \\
\hline & $N^{2}$ citaços & $(\%)$ & & $\mathrm{N}^{0}$ citaçōes & $(\%)$ \\
\hline Acima de $5 \%$ & & & Acima de $5 \%$ & & \\
\hline $\begin{array}{l}\text { Gripe } \\
\text { Dor de barriga } \\
\text { Febre } \\
\text { Dor de cabeça } \\
\text { Dor de garganta }\end{array}$ & $\begin{array}{r}23 \\
13 \\
10 \\
8 \\
5\end{array}$ & $\begin{array}{r}(32,4) \\
(18,3) \\
(14,0) \\
(11,3) \\
(7,0)\end{array}$ & $\begin{array}{l}\text { Gripe } \\
\text { Dor de barriga } \\
\text { Diarréia } \\
\text { Febre } \\
\text { Dor de barriga }\end{array}$ & $\begin{array}{r}18 \\
10 \\
8 \\
6 \\
5\end{array}$ & $\begin{array}{r}(31,6) \\
(17,5) \\
(14,0) \\
(10,5) \\
(8,8)\end{array}$ \\
\hline Abaixo de $5 \%$ & & & Abaixo de $5 \%$ & & \\
\hline $\begin{array}{l}\text { Bronquite, Diarréia, Dor de dente } \\
\text { Alcoolismo, Asma, Caxumba, } \\
\text { Coluna, Nariz entupido, Vômitos }\end{array}$ & $\begin{array}{l}2 \\
1\end{array}$ & $\begin{array}{l}(2,8) \\
(1,4)\end{array}$ & $\begin{array}{l}\text { Catapora, Garganta, Sarampo } \\
\text { Estomago, Rins, Inflamaçōes, } \\
\text { Verminoses }\end{array}$ & $\begin{array}{l}2 \\
1\end{array}$ & $\begin{array}{l}(3,5) \\
(1,7)\end{array}$ \\
\hline $\begin{array}{l}\text { Total de cltaçōes } \\
\qquad \quad p>0,05\end{array}$ & $71^{*}$ & & $\begin{array}{l}\text { Total de citaçōes } \\
\star \quad p>0,05\end{array}$ & 57 & \\
\hline
\end{tabular}

ser tratadas com remédios caseiros está mostrada na Tabela 2. Dentre as doenças e sintomas mais citados pelos alunos estão: a gripe, a dor de barriga, a febre e a dor de cabeça. Ressalta-se que os alunos de primeira e segunda séries apontam um número de doenças bem maior (71 citaçōes) do que os alunos de terceira e quarta séries ( 57 citaçðes). Somente $4(3,1 \%)$ crianças associaram a doença ao remédio caseiro (gripe/hortelã, gripe/canela queimada, gripe/folha de laranja e doença renal/ folha de amora).

A relação das plantas medicinais e/ou remédios caseiros identificados pelas crianças é mostrada na Tabela 3. Esta tabela indica que os chás de boldo, folha de laranja e erva cidreira são os mais populares entre os alunos de todas as séries estudadas. Treze $(16,2 \%)$ crianças das primeira e segunda séries e $32(39,0 \%)$ alunos das terceira e quarta séries nāo deram respostas. Observa-se aqui tamberm que o número de ervas citadas pelos alunos das primeira e segunda séries superam o das terceira e quarta séries (67 e 50 citações, respectivamente).

A opinião a respeito dos resultados dos remédios caseiros entre os alunos das primeiras séries, mostra que $17(21,2 \%)$ deixaram de responder, 63 $(78,7 \%)$ responderam a questão, $61(96,8 \%)$ acham que dão bons resultados, $2(3,2 \%)$ disseram que não davam.

Opiniōes dos alunos sobre as doenças que podem ser tratadas com rezas e benzedeiras - Ao se questionar os alunos das primeira e segunda séries se rezam quando alguém adoece, $69(82,2 \%)$ disseram que sim e $11(13,7 \%)$ disseram nāo.
Quanto ao tratamento com as benzedeiras, esses alunos enumeram as seguintes doenças: generalizadas (qualquer doença) $13,7 \%$; dor de cabeça $7,5 \%$; gripe $7,5 \%$; febre $6,2 \%$; bronquite, espinhela carda $2,5 \%$; pessoa aguada, doença na bexiga, câncer, catapora, caxumba, diarréia, dor de barriga, dor no braço, engasgo em pessoas e animais, incorporação espiritual, inflamação, insolação, inchaço, quebranto, queda e tosse $1,2 \%$ cada. Uma criança respondeu que toda doença sem cura pela medicina tradicional poderá obter resultados positivos na benzedeira. Utilizam as benzedeiras e/ou rezadeiras $43(53,7 \%)$ e $66(82,5 \%)$ acham que a oração pode curar doenças (Tabela 4). Um grande percentual de crianças das terceira e quarta séries $38(46,3 \%)$, responderam que se utilizam de rezas para curar doenças. Dentre as doenças que acreditam ser curadas por rezas estão: dor de cabeça $(4,9 \%)$; quebranto, alcoolismo, cobreiro, febre e todas as doenças $(3,6 \%)$; dor de dente, enxaqueca, gripe, machucados em geral, mal olhado, soluço e tentações $(2,4 \%)$; ventre virado, alergia, bronquite, cólicas, dor de barriga, dor de ouvido, desmaio, dormência, espinhela caída, falta de apetite, insolação, manchas na pele, perna machucada, raiva, reumatismo, sangue contaminado e sarampo $(1,2 \%)$. Utilizarn benzedeiras para curar doenças, $67(83,7 \%)$ alunos e $38(46,3 \%)$ acham que a oraçåo pode curar doenças (Tabela 4).

Relaçâa dos remédios caseiros mais indicados, as partes mais utilizadas e forma de preparação. Dentre os remédios mais indicados pelos professores e alunos das quatro escolas estăo: o boldo (folha, infusão e suco); laranjeira - (folha e casca, 
Tabela 3 - Relaçáo de plantas medicinais elou remédios caseiros citados pelos alunos de primeira à quarta séries do primeiro grau de escolas municipais da periferla de Belo Horizonte, Minas Gerais. N. 117.

\begin{tabular}{|c|c|c|c|c|c|}
\hline \multirow[t]{2}{*}{ Plantas medicinais } & \multicolumn{2}{|c|}{$1^{\ell}$ a $2^{\natural}$ séries } & \multirow[t]{2}{*}{ Plantas medicinais } & \multicolumn{2}{|c|}{$3^{n}$ a $4^{n}$ séries } \\
\hline & $N^{2}$ citaçōes & $(\%)$ & & $N^{\dagger}$ citaçōes & $(\%)$ \\
\hline Acima de $5 \%$ & & & Acima de 5\% & & \\
\hline $\begin{array}{l}\text { Boldo } \\
\text { Erva Cidreira } \\
\text { Folha de Laranja }\end{array}$ & $\begin{array}{r}12 \\
11 \\
8\end{array}$ & $\begin{array}{l}\{18,0) \\
(16,4) \\
(11,9)\end{array}$ & $\begin{array}{l}\text { Folha de Laranja } \\
\text { Boldo }\end{array}$ & $\begin{array}{r}14 \\
6\end{array}$ & $\begin{array}{l}(28,0) \\
(12,0)\end{array}$ \\
\hline Abaixo de $5 \%$ & & & Abaixo de $5 \%$ & & \\
\hline Alecrim, Marcela o/ou Marcelina & 3 & $(4,5)$ & Alfavaca, Poejo, Quebra-pedra & 4 & $(8,0)$ \\
\hline $\begin{array}{l}\text { Camomila, Folha de Goiaba, } \\
\text { Hortela, Folha de Mamão, Folha de } \\
\text { Manga, Folha de Pitanga, Funcho, } \\
\text { Limáo com Mel, Rosa Branca }\end{array}$ & 2 & $(3,0)$ & $\begin{array}{l}\text { Enva Cidreira } \\
\text { Alho com folha de Melảo, Limāo, } \\
\text { Panacéla, Trançagem }\end{array}$ & 3 & $(6,0)$ \\
\hline $\begin{array}{l}\text { Chiqueri, Cravo Amarelo, Erva } \\
\text { Doce, Folha de Abacate, Macá, } \\
\text { Maracujá, Orelha de Cachorro, } \\
\text { Picão, Poejo, Quebra-pedra, } \\
\text { Romá verde, Santa Maria }\end{array}$ & 1 & $(1,5)$ & $\begin{array}{l}\text { Canela, Casca de Fomă, Folha de } \\
\text { Algodăo, Folha de Amora, Hortelă, } \\
\text { Sabugueiro, Salsa parrilha }\end{array}$ & 1 & $(2,0)$ \\
\hline $\begin{array}{l}\text { Total de citaçōes } \\
* \quad p>0,05\end{array}$ & $67^{*}$ & & & 50 & \\
\hline
\end{tabular}

Tabela 4 - Costumes familiares sobre tratamento com oraçōes $\theta$ benzedeiras e/ou rezadeiras dos alunos das primeira a quarta séries de escolas municipais da periferia de Belo Horizonte, Minas Gerais. N. 162.

\begin{tabular}{|c|c|c|c|c|c|c|}
\hline \multirow[t]{2}{*}{ Costumes familiares } & \multicolumn{3}{|c|}{$1^{2}$ e $2^{4}$ sérles $\left(n^{9} B 0\right)$} & \multicolumn{3}{|c|}{$3^{*}$ e $4^{4}$ séries $\left(n^{0} 82\right)$} \\
\hline & $\operatorname{sim}_{n^{2}(\%)}$ & $\begin{array}{c}\text { Não } \\
n^{2}(\%)\end{array}$ & $\begin{array}{l}\text { Näo sabe } \\
\Pi^{\circ}\langle \%\rangle\end{array}$ & $\operatorname{Sim}_{n^{\circ}(\%)}$ & $\begin{array}{c}\text { Năo } \\
n^{2}(\%)\end{array}$ & $\begin{array}{c}\text { Năo sabe } \\
n^{0}(\%)\end{array}$ \\
\hline $\begin{array}{l}\text { Utilizam as benzedeiras } \\
\text { e/ou rezadelras }\end{array}$ & $43(53,7)$ & $23(28,7)$ & $14(17,5)$ & $43(52,4)$ & $37(45,1)$ & $2(2,4)$ \\
\hline Oraçăo pode curar doenças & $67^{\star}(83,7)$ & $9(11,2)$ & $4(5,0)$ & $38(46,3)$ & $19(23,2)$ & $25(30,5)$ \\
\hline
\end{tabular}

infusão, decocção, suco); mel (líquido viscoso, favo); poejo (flor, infusăo, decoç̧āo); hortelă (folha, infusāo, decocçāo).

\section{Comentárlos}

Saloca", mostra, em estudo feito no Rio de Janeiro, onde os usuários que utilizam plantas medicinais como medicamentos pertenciam, quase sempre, a familias de condições socioeconómicas baixas. Na populaçăo da capital mineira, (Grandi e col.6) afirmam que a procura de ervas medicinais entre pessoas de classes sociais mais altas foi mais elevada. Esses resultados podem sugerir mudanças culturais ou de mentalidade das populações e/ou diferenças regionais, como também, alternativas pelas perdas econômicas entre as populaçōes, em conseqüência das condiçōes socioeconômicas e políticas presentes no país.

Como mostram os estudos de (Grandi e col..$^{6}$ ) e Grandi e Siqueira ${ }^{7}$ ), todas as classes sociais fazem uso de plantas medicinais como alternativa de tratamento, podendo-se também considerar a influência do fluxo migratório que foi disseminando esses comportamentos, nåo só para as pequenas comunidades, mas para os grandes centros urbanos. Por esse motivo (Barros') chama atenção para as dificuldades de identificaçāo das ervas medicinais, pois a nomeclatura usada na identificaçāo das mesmas difere de acordo com a região.

Comparando os resultados obtidos no presente estudo e, no trabalho de Commune ${ }^{3}$ pode-se veri- 
ficar uma similaridade na identificação das plantas medicinais, como também, os efeitos de cura a elas relacionadas, que se enquadram na caracterização dessa autora ${ }^{3}$, referente ao saber popular de todo o Vale do Jequitinhonha, MG.

Um outro aspecto primordial está relacionado à falta de "cuidados" na utilização das plantas medicinais. Embora a confiança nesses medicamentos seja benéfica para algumas pessoas (efeito placebo), a informação fidedigna é fundamental. Gottlieb e Kaplan ${ }^{5}$ enfatizam o desconhecimento da variação a que estão sujeitos os vegetais (época de colheita, cuidados no processo de armazenamento, secagem e moagem e da contaminaçăo por fungos e microorganismos), podendo assim levá-los a ter atividades curativas, bem como efeitos colaterais.

Além de utilizarem as plantas medicinais para o tratamento de variados sintomas, um pouco mais de $50 \%(86(53,1 \%))$ de dois grupos de indivíduos estudados primeira e segunda séries e terceira e quarta séries vivem entre famílias que procuram benzedeiras como alternativas de cura para suas doenças, $105(64,8 \%)$ dos alunos acreditam que a oração pode curar o mal físico.

E relevante chamar atenção para as respostas das crianças das primeira e segunda séries que

\section{Referências Bibliográficas}

1. BARROS, M.A.G. Plantas medicinais: uso e tradiçòes em Brasilia, DF. Oreades, 1981/1982. Boletim do Departamento de Botânica do ICB/UFMG, 8 (14/15), 1987.

2. CAMARGO, M.T.L. de A. A medicina popular: aspectos metodológicos para pesquisa garrafada. Såo Paulo, Alned Editora e Livraria Ltda, 1985.

3. COMMUNE, I. A. Recursos da natureza para a saúde: cartilha de saúde. Araçuaí, Diocese de Araçuaí, 1984

4. CLRY, J.R. O ensino de $1^{\circ}$ grau e a universidade. Educ. $e$ Rev., 3: 8-11, 1986.

5. GOTTLIEB, O. \& KAPLAN, M.A. Das plantas medicinais aos fărmaços naturais. Ciênc. Hoje, 15: 51-4, 1993.

6. GRANDI, T.S.M.; TRINDADE, J. A.; PINTO, M.J.F; FERREIRA, L.L.; CATELLA, A.C. Plantas medicinais de Minas Gerais, Brasil, Acta Botan. Bras., 3: Supl. 1989 apresentam número maior de crianças que acreditam no poder das oraçōes $(83,7 \%)$ Tabela 4 . Ao se separar essas séries por escola, verifica-se que os resultados são constantes entre elas, sugerindo que, por serem crianças mais jovens, possuem sua referência interna baseada no comportamento familiar. Quanto às crianças das terceira e quarta séries, já têm sua referência no externo, no grupo, nos jogos, símbolos e mitos. Essas crianças tornam-se mais críticas e mais independentes da família, tendem a ser mais envolvidas consigo mesmas e com o grupo, conseqüentemente, mudam os valores e conceitos do vivido (Mussen e col. $\left.{ }^{9}, 1977\right)$. Por outro lado, chamamos a atençăo para o aumento de um possível "preconceito" entre essas crianças que negam orações demonstrando uma possível atitude crítica (Tabela 4).

O estudo mostrou que a medicina popular é conhecida e utilizada pela população estudada e proporcionou o conhecimento das representaçōes desses indivíduos em relação à medicina alternativa.

Sendo assim, é necessário desenvolver e ampliar as possibilidades já existentes da discussăo crítica e construtiva a este respeito, dentro da escola, no programa de educação em saúde.
7. GRANDI, T.S.M.; \& SIQUEIRA, D.M. Flora medicinal de Belo Horizonte: pesquisa dos ervários. In: Congresso de Botânica, 25․ Manaus, 1984, Anais. Brasília, 1990 p. $125-37$.

8. LOZOYA, X. A escola do fururo é o passado. Saúde do Mundo, (junho): 5-7, 1983.

9. MUSSEN, P.H.i CONGER, J.J.; KAGAN, J. Desenvolvimento e personalidade da criança. $4^{a}$ ed. Sào Paulo, Editora Harper \& Row do Brasil, 1977.

10. OLIVEIRA, E.R. O que é medicina popular. São Paulo, Abril Cultural/Brasiliense, 1985.

11. SALOCA, H.R. Apud Grandi, T.S.M. Flora medicinal de Belo Horizonte. Sociedade Botânica do Brasil, 1990.

12. VAN DEN BERG, M.E. Plantas medicinais na Amazônia: contribuição ao seu conhecimento sistemático. Belém, CNPq Programa Trópico Úmido/MPEGm, Gráfica Falangola Editora Ltda. 1982. p. 13. 


\begin{abstract}
The knowledge and use of popular cures was investigated as part of health education project in such a way as to develop and expand the existing possibilities for critical and constructive discussion in the school within the health program. It was hoped that this would resuit in the retrieval and in an increase in the value attributed to intormation concerning this nonsystematized knowledge present in a controversial and poonly accepted form in the practices of the population. One hundred and five teachers and 162 students of the 1 st to 4 th grades of the four primary schools on the outskirts of Belo Horizonte were interviowed. One hundred and five of the teachers answered the questions put. Twenty-three $(32,4 \%)$ of the teachers said they believed in special cures, $69(65,7 \%)$ thought that centain diseases could be treated with homemade remedies for these, 54 (78.3\%) were able to associate a particular disease whit a particular medicinal plant and $15(21.7 \%)$ prescribed a treatment without any association with a particular disease, 36 (34.3\%) cited a disease without relating this to a particular herb. One hundred and one $(62,3 \%)$ of the students believed that homemade remedies are effective for certain diseases. Amongst the teachers and students various diseases were mentioned as woll as different symptoms and organs that can be cured by medicinal piants, roots or traditional healers. A little more than $50 \%$ of the two groups of students (1st and 2nd grade, 3rd and 4th grade) live in families who make use of traditional healers to provide alternative cures. More than 36 plants or preparations of parts of plants were indicated by the teachers and students. It is conclude that these individuals possess knowiedge of and do in fact make use of alternative medicine.
\end{abstract}

Knowledge, attitudes, practice. Altermative medicine. Health education. 